\title{
MODEL BISNIS DAN STRATEGI PENGEMBANGAN USAHA PADA THE COFFEE BEAN DAN TEA LEAF (TCBTL)
}

\author{
BUSINESS AND BUSINESS DEVELOPMENT STRATEGY MODELS ON \\ THE COFFEE BEAN AND TEA LEAF (TCBTL)
}

\author{
Bambang Trenggono*), Arief Daryanto**), dan Bunasor Sanim**) \\ *) PT. Girindra \\ Jl. Slalihara No. 11 Jati Padang Pasar Minggu 12520 \\ ${ }^{* *}$ Sekolah Bisnis, Institut Pertanian Bogor \\ Jl. Raya Pajajaran, Bogor 16151
}

\begin{abstract}
Every business requires strategic planning to face the environmental conditions and the existing competition, Including TCBTL. Strategic planning can be done by mapping the existing business model using Business Model Canvas approach. This study aimed to identify TCBTL's business model using Business Model Canvas approach and formulate new strategic program using SWOT analysis by referring to Business Model Canvas approach. The result of the research shows that TCBTL has a component of business model canvas model consisting of customer segmentations, value propositions, channels, customer relationships, revenue streams, key resources, key activities, key partnerships and cost structures. The improvement programs that should be done by TCBTL through the identification of external and internal factors is to optimize the function of the bank as a partner that is able to increase sales through promotional programs to cardholders or customers on the element Key Partners. Key Activities on elements TCBTL that needs to improve is that adding partners to increase cooperation in conducting marketing activities. Then on Key Resources elements, TCBTL needs to make program improvements by designing a strategy to increase the capacity of its human resources.
\end{abstract}

Keywords: business model canvas, TCBTL, cafe, strategic, SWOT analysis

\begin{abstract}
Abstrak: Setiap bisnis membutuhkan perencanaan strategis untuk menghadapi kondisi lingkungan dan persaingan yang ada, termasuk TCBTL. Perencanaan strategis dapat dilakukan dengan memetakan model bisnis yang ada dengan menggunakan pendekatan Business Model Canvas. Penelitian ini bertujuan mengidentifikasi model bisnis TCBTL dengan pendekatan Business Model Canvas dan merumuskan strategis baru dengan menggunakan analisis SWOT dengan mengacu pada pendekatan Business Model Canvass. Hasil penelitian menunjukkan bahwa TCBTL memiliki komponen elemen business model canvas yang terdiri dari customer segmentations, value propositions, channels, customer relationships, revenue streams, key resources, key activities, key partnerships dan cost structures. Program perbaikan yang harus dilakukan oleh TCBTL melalui identifikasi faktor eksternal dan internal adalah mengoptimalkan fungsi bank sebagai mitra yang mampu meningkatkan penjualan melalui program promosi kepada pemegang kartu atau nasabah pada elemen mitra utama. Kegiatan utama elemen yang perlu ditingkatkan TCBTL adalah menambahkan mitra kerja untuk meningkatkan kerjasama dalam melakukan kegiatan pemasaran. Kemudian pada elemen sumber daya manusia, TCBTL perlu melakukan perbaikan program dengan merancang strategi untuk meningkatkan kapasitas sumber daya manusianya.meningkatkan pelatihan karyawan, insentif yang transparan dan rutin serta merancang strategi peningkatan kapasitas SDM yang dimiliki.
\end{abstract}

Kata kunci: business model canvas, TCBTL, kafe, strategi, Analisis SWOT

\footnotetext{
${ }^{1}$ Alamat Korespondensi:

Email: bambangtrenggono@ymail.com
} 


\section{PENDAHULUAN}

Kopi merupakan salah satu hasil komoditi perkebunan yang memiliki nilai ekonomis yang cukup tinggi di antara tanaman perkebunan lainnya dan berperan penting sebagai sumber devisa negara. Kopi tidak hanya berperan penting sebagai sumber devisa melainkan juga merupakan sumber penghasilan bagi tidak kurang dari satu setengah juta jiwa petani kopi di Indonesia (Rahardjo, 2012). Meskipun demikian, Indonesia tercatat sebagai negara produsen kopi tebesar ketiga di dunia setelah Brasil dan Vietnam. Namun, jika dilihat dari sisi konsumsinya sendiri ternyata masih jauh di bawah konsumsi negara Brasil, bahkan jauh di bawah negara-negara yang bukan sebagai negara produsen kopi. Sebagai gambaran, kebutuhan kopi di Indonesia pada tahun 2014 tiap $60 \mathrm{~kg}$ (1 bag) mencapai 4.167.000, sementara Brasil 20.771.000, Uni Eropa 41.779.000, Amerika Serikat 23.761.000, Jepang 7.494 000, Russia 4.033.000, dan Canada 3.913.000 (ICO, 2014). Jika ditelaah lebih lanjut, pada tahun 2014 konsumsi kopi di Indonesia hanya sebesar $1,03 \mathrm{~kg} / \mathrm{kapita}$, di mana konsumsi kopi di Brasil sudah mencapai $3 \mathrm{~kg} / \mathrm{kapita}$, bahkan Finlandia yang bukan negara produsen kopi, konsumsinya mencapai 8-10 kg/kapita (AEKI, 2014).

Menurut Kara et al. (1997) dinamika perkembangan zaman telah mengubah pola konsumsi masyarakat global dalam hal mengkonsumsi makanan dan minuman, dari semula mengkonsumsi makanan dan minuman di dalam rumah menjadi di luar rumah. Ditambahkan oleh Mawson dan Fearne (1996) alasan utama masyarakat mengonsumsi makanan dan minuman di luar rumah karena adanya perubahan demografi, meningkatnya pendapatan, kenyamanan dan kemudahan dalam mendapatkan makanan atau minuman, serta meningkatnya aktifitas rekreasi masyarakat. Seiring dengan bergesernya pola konsumsi tersebut, maka peluang untuk pengembangan bisnis di bidang industri makanan dan minuman sangat terbuka luas.

Kota-kota besar di Indonesia pertumbuhan cafe yang menawarkan kopi mengalami persaingan yang amat ketat. Para pelaku bisnis itu melirik pangsa pasar Indonesia karena dianggap sangat potensial bagi perkembangan bisnis ini (Kurniawan dan Ridlo, 2017). Munculnya cafe di berbagai kota besar di Indonesia tidak hanya menguntungkan pemilik cafe itu sendiri, tetapi juga membuka peluang bagi pencari kerja. Hadirnya cafe juga melahirkan fenomena sosial dan budaya baru. Cafe bukan lagi sebagai tempat untuk minum teh, kopi, menyantap makanan ringan dan untuk melepas kejenuhan dan melewatkan waktu saja, namun cafe juga dijadikan sebagai tempat tempat berkumpul, bersosialisasi, bertukar pikiran, memperluas jaringan dan berbisnis (Salendra, 2014). Jumlah cafe yang semakin meningkat ini juga menimbulkan persaingan yang semakin ketat dan pelaku usaha harus mampu menganalisis faktor-faktor dominan apa saja yang memengaruhi konsumen dalam memilih cafe.

The Coffee Bean and Tea Leaf (TCBTL) adalah sebuah rantai kopi Amerika didirikan pada tahun 1963, merupakan perusahaan yang bergerak di bidang specialty coffee and tea paling tua dan terbesar di Amerika Serikat. Tahun 1996 TCBTL memperluas usahanya baik di Amerika Serikat dan internasional, dengan membuka gerai pertama di Singapura pada tahun 1996, dan di Malaysia pada tahun berikutnya. Perusahaan ini dikenal untuk original ice blended kopi dan teh, minuman kopi panas dan minuman teh panas dan es. Di Indonesia TCBTL merupakan cafe waralaba asing pertama di Indonesia, yang berdiri pada tahun 2001, dan berada di bawah lisensi PT Trans Coffee sejak tahun 2006. Hingga saat ini, outlet TCBTL di Indonesia sebanyak 109 outlet.

Cilandak Town Square merupakan salah satu pusat hiburan di daerah Cilandak, Jakarta Selatan yang didirikan pada pertengahan tahun 2002 dan memiliki konsep town square. Daya tarik dari Cilandak Town Square adalah dengan banyaknya pilihan cafe sepanjang promenade, terdapat berbagai bentuk cafe yang menawarkan berbagai jenis minuman dengan suasana cafe yang berbeda, baik yang berasal dari luar negeri antara lain Starbucks, The Coffee Bean and Tea Leaf, Dome, dan Djournal, maupun yang berasal dari dalam negeri seperti Cafe Excelso, Gayo Coffee maupun Kopi Luwak.

Bergesernya pola konsumsi masyarakat berdampak meningkatnya jumlah cafe secara pesat baik brand lokal maupun internasional. Hal ini menunjukkan persaingan di industri cafe ini semakin ketat. Cara memenangkan persaingan atau menjadi pelaku pasar yang memiliki market share terbesar, tentu saja harus memiliki strategi tepat yang diturunkan dari pernyataan visi dan misi perusahaan. Hal yang serupa juga dilakukan oleh TCBTL sebagai cafe waralaba asing pertama di Indonesia. Namun menjadi cafe waralaba 
asing pertama, tidak serta merta menjadi pemimpin pasar atau cafe waralaba yang memiliki jumlah cafe terbanyak dikelasnya. Jika dibandingkan dengan pesaing terdekatnya yaitu cafe Starbucks yang juga sama-sama cafe waralaba asing di Indonesia, jumlah cafe yang dimiliki TCBTL masih dibawah Starbuck. Sebagai gambaran, jumlah cafe starbuck pada akhir tahun 2014 telah mencapi 200 gerai dan pada tahun 2015 akan membuka 25 gerai lagi (Bachdar, 2014). Jika dilihat dari sisi ekuitas merek menurut Widjadja dan Jokom et al. (2007) Starbucks merupakan coffee shop yang kesadaran mereknya paling banyak diingat oleh responden, diasosiasikan paling positif dan loyalitas mereknya paling tinggi jika dibandingkan dengan TCBTL.

Masih rendahnya tingkat konsumsi kopi di Indonesia dapat dinilai sebagai peluang usaha yang masih terbuka luas, secara langsung maupun tidak langsung berdampak pada semakin bertambahnya jumlah cafe terutama di kota-kota besar di Indonesia. Jumlah cafe yang semakin banyak satu sisi dapat memberikan alternatif pilihan yang makin beragam pada konsumen, namun dilain pihak juga dapat meningkatkan intensitas persaingan dalam industri. Setiap pelaku usaha cafe memerlukan perencanaan strategis guna menghadapi kondisi lingkungan dan persaingan saat ini, salah satunya dengan memetakan model bisnis. Model bisnis merupakan alat analisis yang sangat aplikatif dan dapat diterapkan di berbagai jenis atau bentuk usaha, organisasi maupun berbagai jenis lingkungan bisnis (Leschke, 2013), salah satunya adalah pendekatan menggunakan Business Model Canvas (BMC) (Florencia, 2015); Rytkonen and Nenonen (2013) Business model canvas memiliki keunggulan karena berhasil mengubah konsep model bisnis yang rumit menjadi sederhana (Muller et al. 2011). Tujuan dari penelitian ini adalah untuk mengidentifikasi model bisnis pada outlet TCBTL di Cilandak Town Square dengan pendekatan BMC, serta membuat perbaikan model bisnis outlet TCBTL di Cilandak Town Square.

\section{METODE}

Penelitian ini dilakukan di outlet TCBTL yang terletak di pusat perbelanjaan modern Cilandak Town Square. Penentuan tempat ini dilakukan secara sengaja (purposive) dengan pertimbangan bahwa di tempat tersebut memiliki konsep hiburan dan menawarkan banyak cafe, serta memiliki pengunjung yang banyak dengan karakteristik yang beragam. Pengumpulan data penelitian ini dilakukan pada bulan Agustus 2015.

Metode penelitian yang dilakukan adalah dengan menggunakan metode deskriptif dengan pendekatan studi kasus. Penelitian dengan pendekatan studi kasus pada outlet TCBTL di Cilandak Town Square Jakarta dilakukan dengan mengumpulkan berbagai data untuk menjawab permasalahan yang ada, khususnya kajian strategi di masa yang akan datang. Penelitian dilakukan untuk mendapatkan analisis tentang kondisi lingkungan internal maupun eksternal perusahaan yang akan diwakili oleh sembilan elemen yang ada pada bisnis model kanvas yang nantinya akan digunakan untuk menghasilkan SWOT yang ada pada outlet TCBTL di Cilandak Town Square Jakarta. Jenis data dalam penelitian ini adalah data primer dan data sekunder. Data primer diperoleh dari beberapa sumber data, antara lain pengamatan langsung di lapangan (observasi), wawancara dengan pihak manajemen industri di pusat perbelanjaan modern Cilandak Town Square, wawancara dengan pelaku usaha cafe, yaitu store manager dan barista. Data primer diantaranya data untuk analisis faktor internal dan eksternal perusahaan untuk analisis SWOT, visi dan misi, tujuan dan sasaran, struktur organisasi, kondisi persaingan, dan kompetensi yang dimiliki.

Data sekunder diperoleh dari berbagai sumber literatur dan bacaaan lainnya, seperti buku, jurnal, internet, media massa, pendapat para ahli dan artikel serta publikasi data dari perusahaan maupun instansi yang terkait dengan penulisan penelitian ini baik pemerintah maupun swasta. Data sekunder diantaranya data perkembangan industri cafe, data demografi Jakarta Selatan, customer segmentation, data tahunan target proyeksi sasaran, cost structures, arus pendapatan, dan pangsa pasar.

Teknik penentuan responden menggunakan teknik purposive sampling maka penulis secara langsung memilih sendiri pihak-pihak yang menjadi responden yang terdiri dari store manager satu orang dan barista tiga orang. Analisis deskriptif dilakukan dengan mengkaji dan mengintrepretasi data yang diperoleh dari hasil observasi, wawancara dan studi dokumentasi mengenai informasi kondisi outlet TCBTL di Cilandak Town Square Jakarta secara menyeluruh baik dari sisi internal maupun eksternal perusahaan. Analisis 
deskriptif kualitatif ini menggunakan pendekatan non statistik. Hasil yang didapat berupa pemahaman peneliti mengenai visi, misi, norma dan nilai-nilai yang menjadi landasan organisasi dalam menjalankan kegiatannya. Pemahaman ini menjadi catatan bagi peneliti ketika merumuskan model perbaikan dan strategi pengembangan.

Identifikasi model bisnis akan dilakukan menggunakan pendekatan BMC dengan melakukan analisis pada sembilan elemen BMC, kemudian melakukan analisis internal dan eksternal terhadap kesembilan elemen BMC tersebut. Analisis SWOT dalam penelitian ini merupakan pengetahuan mengenai faktor internal dan eksternal yang memengaruhi organisasi dari sudut pandang organisasi sebagai pelaku atau pengelola organisasisehinggadidapatkankekuatandankelemahan, serta peluang dan ancaman. Hasil dari analisis SWOT digunakan peneliti untuk melakukan perbaikan terhadap model bisnis pada outlet TCBTL di Cilandak Town Square Jakarta saat ini. Peneliti menggunakan hasil kombinasi dari kekuatan, kelemahan, peluang dan ancaman menjadi suatu faktor perubahan pada model bisnis perbaikan. Setelah melakukan tahapan perbaikan model bisnis, peneliti dapat merumuskan strategi dan implikasi manajerial yang berasal dari hasil analisis SWOT dan perubahan-perubahan yang terjadi pada model bisnis. Hasilnya berupa satu atau beberapa strategi pengembangan outlet TCBTL di Cilandak Town Square Jakarta.

Penelitian ini bertujuan mengidentifikasi model bisnis pada outlet TCBTL di Cilandak Town Square dengan pendekatan Business Model Canvas, serta membuat perbaikan model bisnis outlet TCBTL di Cilandak Town Square. Langkah selanjutnya adalah memetakan model bisnis seperti apa yang dimiliki saat ini dengan melihat kondisi lingkungan dan aktivitas bisnis saat ini. Selanjutnya masuk ke dalam analisis lingkungan internal dan eksternal perusahaan dengan menggunakan pendekatan BMC. Setelah memetakan kondisi model bisnis, dilakukan analisis SWOT dari ke-sembilan building blocks yang terkandung di dalam konsep BMC. Sembilan building blocks ini juga merupakan perpaduan kondisi internal dan eksternal perusahaan. Setelah melakukan analisis SWOT maka dapat dipetakan model bisnis yang baru yang merupakan perbaikan dan penyempurnaan dari model bisnis sebelumnya. Secara keseluruhan sistematika penelitian dituangkan pada kerangka pemikiran konseptual yang digambarkan pada Gambar 1.

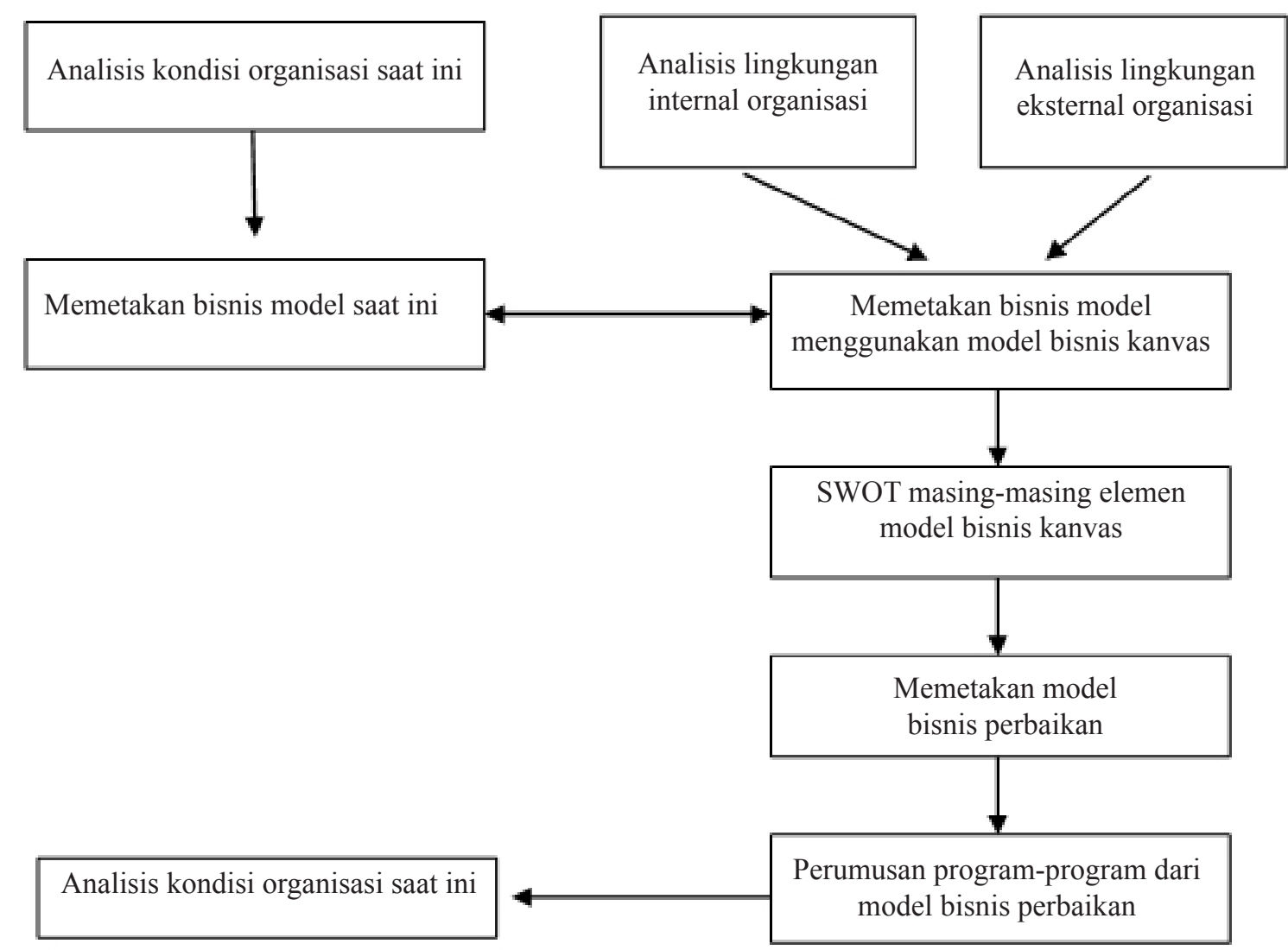

Gambar 1. Kerangka pemikiran penelitian 


\section{HASIL}

\section{Identifikasi Elemen Model Bisnis Pada TCBTL di Cilandak Town Square}

\section{Key partners}

TCBTL memiliki mitra kunci (key partners) yang terdiri dari petani kopi dari Amerika Latin, Afrika Timur dan Asia Pasifik yang memasok bahan baku ke outlet-outlet TCBTL di seluruh Amerika Serikat dan Asia. Khusus untuk cabang atau outlet di Indonesia, TCBTL juga memiliki pemasok yang berasal dari dalam negeri yang memasok $20 \%$ bahan baku kopi lokal yang berasal dari Sumatera dan Sulawesi. Menurut Silalahi (2014) key partners memiliki kaitan erat dengan elemen-elemen lainnya. Perusahaan atau organisasi dapat menentukan untuk mengadakannya sendiri atau melakukan kerjasama dengan mitra kerjanya.

\section{Key activities}

Aktivitas kunci (key activities) yang dilakukan oleh TCBTL menjual produk mereka melalui outlet TCBL yang ada di Cilandak Town Square. TCBTL di Indonesia yang dikelola oleh Trans Corporation melalui PT Trans Coffee memiliki sebuah toko online, dan sudah menjual mesin pembuat kopi (coffee maker), sehingga memungkinkan pelanggan dapat membeli biji kopi dan mesin kopi untuk menikmati minuman panas berkualitas tinggi di rumah mereka sendiri. Penjualan produk teh di TCBTL tidak termasuk aktivitas utama. Penjualan produk teh di TCBTL dilakukan untuk mendapatkan konsumen yang tidak menyukai kopi. Menurut (Lamarque, 2005) agar organisasi dapat terus bertahan maka harus memiliki key activities yang berbeda dengan para kompetitor atau bisa saja memiliki key activities yang sama dengan kompetitor namun dengan cara yang berbeda.

\section{Key resources}

Key resources merupakan aset atau sumber daya yang dimiliki dan diperlukan perusahaan agar proses bisnis dapat berjalan sesuai tujuan. TCBTL menempatkan penekanan yang kuat dalam memberikan layanan terbaik dalam misi dan nilai-nilai mereka, dan menjaga misi dan nilai-nilai yang relevan di semua outlet mereka, menjaga kinerja merek. Pelatihan khusus diberikan kepada staf untuk menjadi lebih baik dalam memberikan layanan kepada konsumen. TCBTL secara rutin mengikutsertakan barista pada berbagai kompetisi, baik tingkat nasional maupun tingkat internasional. Kompetisi ini bertujuan untuk memberikan apresiasi serta peningkatan kreativitas pada barista di seluruh negara-negara pemegang lisensi TCBTL. Menurut Stefan and Richard (2014) key resources mencakup sumberdaya nyata (fasilitas produksi, bangunan, kendaraan, dan peralatan) dan sumberdaya intelektual (merek, pengetahuan, paten, hak cipta, kemitraan, database pelanggan, staf dan manajer)

\section{Cost structure}

Cost structures merupakan komposisi biaya yang dibutuhkan untuk dapat menciptakan dan memberikan nilai kepada pelanggan (value proposition dan channels), menjaga hubungan baik dengan pelanggan (customer relationships), sebagai upaya mendapatkan pendapatan (revenue streams), menjalankan aktivitas bisnis (key activities), mendapatkan dan mengelola sumber daya (key resources), serta bekerja sama dengan mitra kerja (key partnerships). Menurut Qastharin (2016) cost structure merupakan semua biaya yang dikeluarkan untuk menjalankan bisnis.

Terhadap cost structure (struktur biaya). TCBTL mengalokasikan biaya mereka diberbagai sektor antara lain seperti iklan, peralatan, bahan baku, sumber daya manusia, dan biaya transportasi. TCBTL adalah perusahaan digerakkan oleh nilai atau yang disebut juga value driven company, yang berarti bahwa mereka berfokus pada memaksimalkan nilai produk dan layanan mereka daripada berfokus pada meminimalkan biaya. Alokasi struktur biaya pada outlet TCBTL Cilandak Town Square selengkapnya pada Tabel 1.

Tabel 1. Alokasi struktur biaya pada outlet TCBTL Cilandak Town Square

\begin{tabular}{|c|c|c|c|}
\hline Alokasi & Jumlah (Rp) & Persen $(\%)$ & Keterangan \\
\hline Bahan baku & 85 juta & 18,9 & $\begin{array}{l}\text { Omzet } 450 \\
\text { juta/bln }\end{array}$ \\
\hline $\begin{array}{l}\text { Biaya sewa } \\
\text { lokasi }\end{array}$ & 60 juta & 13,3 & Per bulan \\
\hline Gaji & 44 juta & 9,8 & $\begin{array}{l}\text { Untuk } \\
16 \text { orang } \\
\text { karyawan }\end{array}$ \\
\hline $\begin{array}{l}\text { Biaya } \\
\text { perawatan }\end{array}$ & 500 ribu & 0,11 & Per bulan \\
\hline
\end{tabular}


Value proposition

Value proposition merupakan nilai atau manfaat yang ditawarkan perusahaan kepada pelanggannya. Hal inilah yang diharapkan menjadi alasan utama mengapa pelanggan memilih produk atau jasa yang dimiliki perusahaan daripada perusahaan lainnya. Berdasarkan hasil wawancara yang telah dilakukan, proposisi nilai (value proposition) TCBTL yaitu menawarkan untuk pelanggan mereka teh berkualitas tinggi dan kopi bersumber dari lokasi eksotis, serta makanan lezat dan lingkungan yang nyaman untuk makan di toko mereka. TCBTL membedakan diri dari pesaing mereka dengan resep mereka yang unik, biji kopi berkualitas tinggi, dan layanan berkualitas tinggi. TCBTL memiliki kemampuan mempertahankan harga premium untuk produknya, disaat yang sama mereka harus mempertahankan pelanggan. Hal ini memungkinkan karena mereka memiliki kualitas produk dan layanan yang prima. Menurut Morris (2009); Horvath et al. (2016) mengatakan bahwa sebuah model bisnis yang sukses harus memiliki keunggulan dari value proposition yang dijadikan keunggulan kompetitif untuk meningkatkan hubungan antar elemen yang dimiliki model bisnis.

\section{Customer relationships}

Hubungan dengan pelanggan atau customer relationships menggambarkan jenis hubungan yang dibangun oleh perusahaan dengan segmen pelanggan yang dimilikinya. Pelayanan tatap muka yang ada di TCBTL merupakan ujung tombak dalam membangun hubungan. TCBTL menawarkan pelayanan tatap muka untuk para pelanggan kopi di toko setiap hari. Minuman yang disediakan dibuat secara langsung, toko didesain dengan mengutamakan kenyamanan, dan para pelanggan memungkinkan untuk mendapatkan hadiah atau merchandise setiap melakukan pembelian di dalam toko. Dengan menunjukkan nilai inti (dikenal dengan FROTH, atau Friendly, Respect, Ownership, Teamwork dan Honesty), perusahaan akan menginspirasi atau mendorong semua karyawan TCBTL untuk saling menghormati dan menghargai satu sama lain dan untuk memberikan Total Quality Experience (total pengalaman berkualitas) yang diharapkan oleh para pelanggan ketika mengunjungi TCBTL. Menurut Amanullah et al. (2016); Zoot dan Amit (2013) perusahaan harus memperjelas hubungan dengan pelanggan agar terbentuk hubungan yang baik dengan setiap segmen pelanggan.

\section{Channels}

Saluran pendistribusian untuk bahan baku dan produk lain dilakukan oleh distributor pihak ketiga. Dengan menggunakan pihak ketiga yang lebih profesional, TCBTLakan lebih fokus dalam kegiatan operasionalnya sesuai nilai inti yang dianut. Bahan baku dan produk dari TCBTL di seluruh dunia, termasuk TCBTL Cilandak Town Square, dipasok oleh pihak ketiga yang berlokasi di Compton, California. Pengiriman dilakukan secara rutin untuk menjamin kualitas produk. Sejak diberlakukannya sistem rantai pasok terintegrasi, TCBTL pusat dapat memberikan solusi kepada waralaba yang berbeda dan pelanggan di pasar global, sesuai dengan latar belakang permasalahannya. Franchising atau waralaba merupakan salah satu strategi TCBTL dalam hal penyaluran produknya. TCBTL tidak mengizinkan pemegang lisensi (pewaralaba) untuk melakukan sub-waralaba outlet mereka kepada pihak lain. Hal ini sejalan dengan strategi TCBTL yaitu strategi rantai pasok terintegrasi, yang terpusat pada satu lokasi. TCBTL lebih memilih untuk memiliki seluruh unit bisnis yang ada, dan bukan di sub-waralabakan. Hal ini dilakukan karena mereka memiliki target pasar ceruk (niche) dan bukannya produk massal. Menurut Fielt (2013); Teece (2009) channels merupakan cara bagaimana perusahaan berkomunikasi dan mencapai segmen pelanggannya untuk menyampaikan proporsi nilai perusahaan tersebut berupa saluran komunikasi, distribusi dan penjualan langsung dengan pelanggan.

\section{Customer Segments}

Hasil penelitian, terdapat beberapa segmen konsumen yang berbeda di TCBTL yang pertama adalah konsumen yang berusia 18-40 tahun. Konsumen yang berada pada segmen ini sebagian besar merupakan pelajar, remaja, pegawai kantoran dan orang tua yang bekerja. Konsumen jenis ini, menganggap kopi dan teh sebagai bagian dari gaya hidup mereka dalam upaya meringankan tekanan akibat pekerjaan, sekolah, atau kehidupan sehari-hari. Segmen ini diidentifikasikan dengan kaum muda, urban dan professional (YuppiesYoung, Urban dan Proffesional). Jika dielaborasi lebih lanjut, konsumen yang berkunjung ke TCBTL $80 \%$ nya pengguna kartu kredit atau kartu debit, sementara sisanya menggunakan cash. Konsumen yang menggunakan cash sebagian besar adalah kaum pelajar atau anak muda yang tidak memiliki daya beli kuat. Berdasarkan observasi, konsumen yang berada pada segmen ini adalah peminum kopi maupun teh 
sebagai gaya hidup atau mengikuti tren saja. Konsumen pada segmen ini tidak berkontribusi secara signifikan terhadap total omset bagi TCBTL.

\section{Revenue streams}

Revenue streams yang dapat disebut juga aliran pendapatan merupakan pemasukan yang diterima perusahaan yang biasanya diukur dalam bentuk uang. Dalam penelitian ini terungkap bahwa secara umum pendapatan TCBTL berasal dari penjualan produk serta pendapatan yang berasal dari produk makanan dan minuman. Berdasarkan wawancara, omzet cabang atau outlet TCBTL sebesar Rp400-450 juta per bulan. Besar kecilnya omset suatu outlet, dipengaruhi oleh penjualan, suasana coffee shop, dan produk subtitusi yang tidak hanya berasal dari coffee shop pesaing, juga berasal dari tempat makan yang mengusung konsep selain coffee shop dengan jenis minuman dan makanan yang lebih beragam. Hasil BMC dari TCBTL tersaji pada Gambar 2.

\section{Analisis SWOT BMC TCBTL}

Perbaikan pada elemen-elemen BMC pada TCBTL dilakukan melalui analisis SWOT dengan mengidentifikasi faktor lingkungan internal maupun eksternal dari masing-masing elemen tersebut. Hasil analisis tersaji pada Gambar 3.

\section{Program Perbaikan BMC Pada TCBTL}

Analisis SWOT menunjukkan kekuatan, kelemahan, peluang serta ancaman yang dimiliki setiap elemen model bisnis sehingga dapat dilihat bagian utama yang perlu diperbaiki dan atau dikembangkan, serta hal-hal apa saja yang perlu dipertahankan atau dihilangkan. Hasil analisis SWOT yang tersaji pada Gambar 3 maka perbaikan-perbaikan yang perlu dilakukan oleh TCBTL untuk masing-masing elemen BMC adalah sebagai berikut:

1. Key partners, berdasarkan analisis SWOT pada elemen key partners maka TCBTL perlu melakukan program perbaikan dengan mengoptimalkan fungsi bank sebagai mitra yang mampu meningkatkan penjualan melalui program promosi kepada pemegang kartu kredit atau nasabah.

2. Key activities, berdasarkan analisis SWOT pada elemen key activites maka TCBTL perlu melakukan program perbaikan dengan meningkatkan kerjasama atau menambah mitra dalam melakukan kegiatan pemasaran, misalnya bank, provider telekomunikasi.

\begin{tabular}{|c|c|c|c|c|}
\hline \multirow[t]{2}{*}{$\begin{array}{l}\quad \text { Key Partners } \\
\text { - Petani Kopi dan teh } \\
\text { - Pemasok Kopi dan } \\
\text { teh } \\
\text { - Pabrik pembuatan } \\
\text { mesin Coffee Maker } \\
\text { - Distributor } \\
\text { - Mitra Pemasaran } \\
\text { - Perbankan }\end{array}$} & $\begin{array}{l}\text { Key Activities } \\
\text { - Tanggung jawab } \\
\text { sosial } \\
\text { - Menjual kopi, teh } \\
\text { berkualitas } \\
\text { - Pembelian + Quality } \\
\text { Control }\end{array}$ & \multirow[t]{2}{*}{$\begin{array}{l}\text { Value Propositions } \\
\text { - Makanan, Kopi, } \\
\text { dan Teh dengan } \\
\text { bahan impor } \\
\text { - kualitas produk, } \\
\text { pelayanan, dan } \\
\text { brand image } \\
\text { - Resep orisinal }\end{array}$} & \begin{tabular}{l}
\multicolumn{1}{c}{ Customer } \\
Relationships \\
- Layanan tatap \\
muka \\
- Dukungan \\
perusahaan \\
pewaralaba
\end{tabular} & \multirow[t]{2}{*}{$\begin{array}{l}\quad \begin{array}{l}\text { Customer } \\
\text { Segments }\end{array} \\
\text { - Pelanggan regule } \\
\text { berusia 18-40 } \\
\text { tahun } \\
\text { - Kaum muda } \\
\text { professional }\end{array}$} \\
\hline & $\begin{aligned} & \text { Key Resources } \\
& \text { - Kopi and teh terbaik } \\
& \text { - Staff terbaik } \\
& \text { - Barista terbaik }\end{aligned}$ & & $\begin{array}{l}\text { Channels } \\
\text { Melalui outlet } \\
\text { (coffee shop) }\end{array}$ & \\
\hline $\begin{array}{l}\text { Cost Structure } \\
\text { - Biaya Iklan } \\
\text { - Biaya Transportasi } \\
\text { - Biaya Peralatan } \\
\text { - Pembelian Bahan Baku } \\
\text { - Biaya Sewa + Overhea } \\
\text { - Biaya tenaga kerja }\end{array}$ & & Penjualan & nue Streams & \\
\hline
\end{tabular}

Gambar 2. Pemetaan BMC dari outlet TCBTL Cilandak Town Square 


\begin{tabular}{|c|c|c|}
\hline Ekternal & $\begin{array}{l}\text { Kekuatan (S) } \\
\text { 1. Price power (kekuatan harga), } \\
\text { TCBTL memiliki kemampuan } \\
\text { mempertahankan harga premium } \\
\text { 2. Memiliki standar nilai-nilai utama } \\
\text { dalam pelayanan yang sudah teruji } \\
\text { 3. Biji kopi dan teh yang berkualitas } \\
\text { dan bermutu tinggi } \\
\text { 4. Membangun komunikasi dan } \\
\text { interaksi langsung dengan } \\
\text { pelanggan yang datang }\end{array}$ & 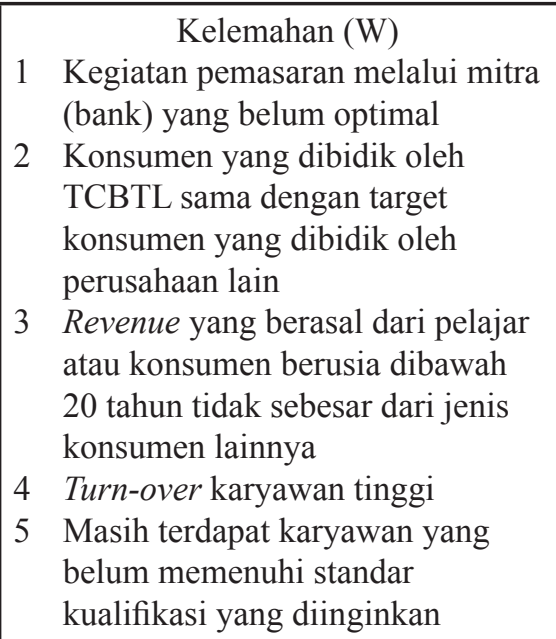 \\
\hline $\begin{array}{l}\text { Peluang }(\mathrm{O}) \\
\text { 1. Kemajuan teknologi, temuan- } \\
\text { temuan mesin pembuat kopi (coffee } \\
\text { maker) } \\
\text { 2. Pengunjung Cilandak Town Square } \\
\text { yang bervariasi } \\
\text { 3. Semakin banyaknya jasa pelatihan } \\
\text { yang dapat memperbaiki kinerja } \\
\text { SDM } \\
\text { 4. Tingginya minat masyarakat } \\
\text { dalam mengonsumsi kopi dan teh } \\
\text { berkualitas tinggi }\end{array}$ & $\begin{array}{l}\text { Strategi S-O } \\
\text { 1. Memperkenalkan jenis minuman } \\
\text { baru dan jenis mesin pengolahan } \\
\text { kopi yang terbaru (S1; O1,O2) } \\
\text { 2. Membangun hubungan dengan } \\
\text { pelanggan melalui pemberian } \\
\text { hadiah atau merchandise setiap } \\
\text { melakukan pembelian di dalam } \\
\text { oulet; (S1;O4) } \\
\text { 3. Bekerja sama dengan konsultan } \\
\text { jasa peningkatan kinerja SDM } \\
\text { outlet TCBTL (S4; O3) }\end{array}$ & $\begin{array}{l}\text { Strategi W-O } \\
\text { 1. Meningkatkan penggunaan media } \\
\text { promosi/mitra promosi (bank, } \\
\text { website, media sosial) kepada } \\
\text { konsumen loyal (W1; O2) } \\
\text { 2. Memaksimalkan program pelatihan } \\
\text { karyawan (W4;O3) } \\
\text { 3. Mempertahankan suasana yang } \\
\text { khas dari TCBTL (W5;O4) } \\
\text { 4. Fokus pada target konsumen yang } \\
\text { lebih spesifik seperti profesional } \\
\text { muda, pebisnis, pengusaha yang } \\
\text { berkunjung ke Cilandak Town } \\
\text { Square (W2; O2, O4) }\end{array}$ \\
\hline $\begin{array}{l}\text { Ancaman (T) } \\
\text { 1. Nilai tukar rupiah terhadap dollar } \\
\text { yang berpengaruh terhadap harga } \\
\text { atau biaya bahan } \\
\text { 2. Perubahan Politik, yang berkaitan } \\
\text { dengan tarif impor, pajak impor, } \\
\text { bea masuk dan lainnya } \\
\text { 3. Semakin banyaknya pesaing yang } \\
\text { memiliki target konsumen yang } \\
\text { sama } \\
\text { 4. Ancaman head hunter yang dapat } \\
\text { 'membajak' SDM yang dimiliki }\end{array}$ & $\begin{array}{l}\text { Strategi S-T } \\
\text { 1. Membina pelanggan regular, } \\
\text { meningkatkan kualitas kopi dan teh } \\
(\mathrm{S} 2, \mathrm{~S} 3 ; \mathrm{T} 1, \mathrm{~T} 2) \\
\text { 2. Meningkatkan pelayanan, } \\
\text { dan menjaga brand image dan } \\
\text { meningkatkan lini produk (S2, S3, } \\
\mathrm{S} 5 ; \mathrm{T} 1, \mathrm{~T} 2, \mathrm{~T} 3)\end{array}$ & $\begin{array}{l}\text { Strategi W-T } \\
\text { Meningkatkan Pelatihan Karyawan, } \\
\text { insentif yang transparan dan rutin } \\
\text { serta merancang strategi peningkatan } \\
\text { kapasitas SDM yang dimiliki } \\
(\text { W4, T4) }\end{array}$ \\
\hline
\end{tabular}

Gambar 3. Hasil analisis SWOT pada TCBTL

3. Key resources, berdasarkan analisis SWOT pada elemen key resources maka TCBTL perlu melakukan program perbaikan dengan merancang strategi peningkatan kapasitas SDM yang dimiliki.

4. Cost structure, berdasarkan analisis SWOT pada elemen cost structure maka TCBTL perlu melakukan program perbaikan dengan melalukan efisiensi khususnya pada biaya operasional.

5. Value proposition, berdasarkan analisis SWOT pada elemen value proposition maka TCBTL perlu melakukan program perbaikan dengan melalukan diversifikasi produk atau layanan yang ditawarkan oleh masing-masing outlet atau toko.

6. Customer relationships, berdasarkan analisis SWOT pada elemen customer relationship maka TCBTL perlu melakukan program perbaikan dengan melalukan peningkatan kapasitas SDM dengan melakukan inhouse training untuk mengingatkan kembali akan nilai inti TCBTL, melakukan strategi peningkatan visibilitas merk. 
7. Channels, berdasarkan analisis SWOT pada elemen channels maka TCBTL perlu melakukan program perbaikan dengan melalukan perubahan mekanisme bekerjasama dengan pihak ketiga dalam hal promosi atau memasarkan produknya.

8. Customer segments, berdasarkan analisis SWOT pada elemen customer segments, maka TCBTL perlu melakukan program perbaikan dengan mengoptimalkan konsumen yang berasal dari kalangan professional muda atau pebisnis (white collar worker).

9. Revenue streams, berdasarkan analisis SWOT pada elemen revenue streams maka TCBTL perlu melakukan program perbaikan dengan melakukan prioritas segmen pelanggan, mengoptimalkan kerjasama dengan pihak lain seperti bank, provider telekomunikasi dalam memasarkan produknya.

Hasil dari indentifikasi lingkungan internal dan eksternal dari masing-masing elemen dalam business model canvas, maka dapat disusun SWOT matriks yang dapat digunakan untuk menyusun perbaikan business model canvas bagi TCBTL, sebagaimana yang telah dibahas pada sub-bab sebelumnya. Hasil penelitian, baik melalui wawancara maupun observasi, perbaikan BMC bagi TCBTL difokuskan kepada empat elemen, yaitu elemen: Key Activites, Customer Segments, Key resources, Value propositions. Pemilihan keempat elemen dalam business model canvas bertujuan sebagai strategi perbaikan bagi TCBTL. Sebagai perusahaan yang berjenis waralaba, baik TCBTL Indonesia sebagai pemegang lisensi maupun outlet/cabang tidak memiliki fleksibilitas dalam melakukan strateginya. Ada beberapa unsur maupun elemen yang memang sudah given yang menjadi standar operasional produk (SOP) dalam menjalankan kegiatan bisnisnya. Namun demikian, dalam hal untuk meningkatlkan omset penjualan, terdapat beberapa elemen yang menjadi kunci dalam peningkatan penjualan cabang atau outlet TCBTL selain dari menjalankan perusahaan sesuai SOP TCBTL Internasional, yaitu perbaikan dengan melakukan fokus kepada pelanggan, dan sumber daya manusia. Key resources dapat berjalan dengan baik maka secara otomatis key activites dapat berjalan dengan baik. Hal ini, pada akhirnya dapat menekan cost structure sehingga dapat meningkatkan revenue streams. Key activities yang berjalan baik tentu saja berpengaruh terhadap value proposition dan customer relationship yang pada akhirnya dapat mengoptimalkan customer segments. Adapun BMC TCBTL setelah perbaikan dapat dilihat pada Gambar 4.

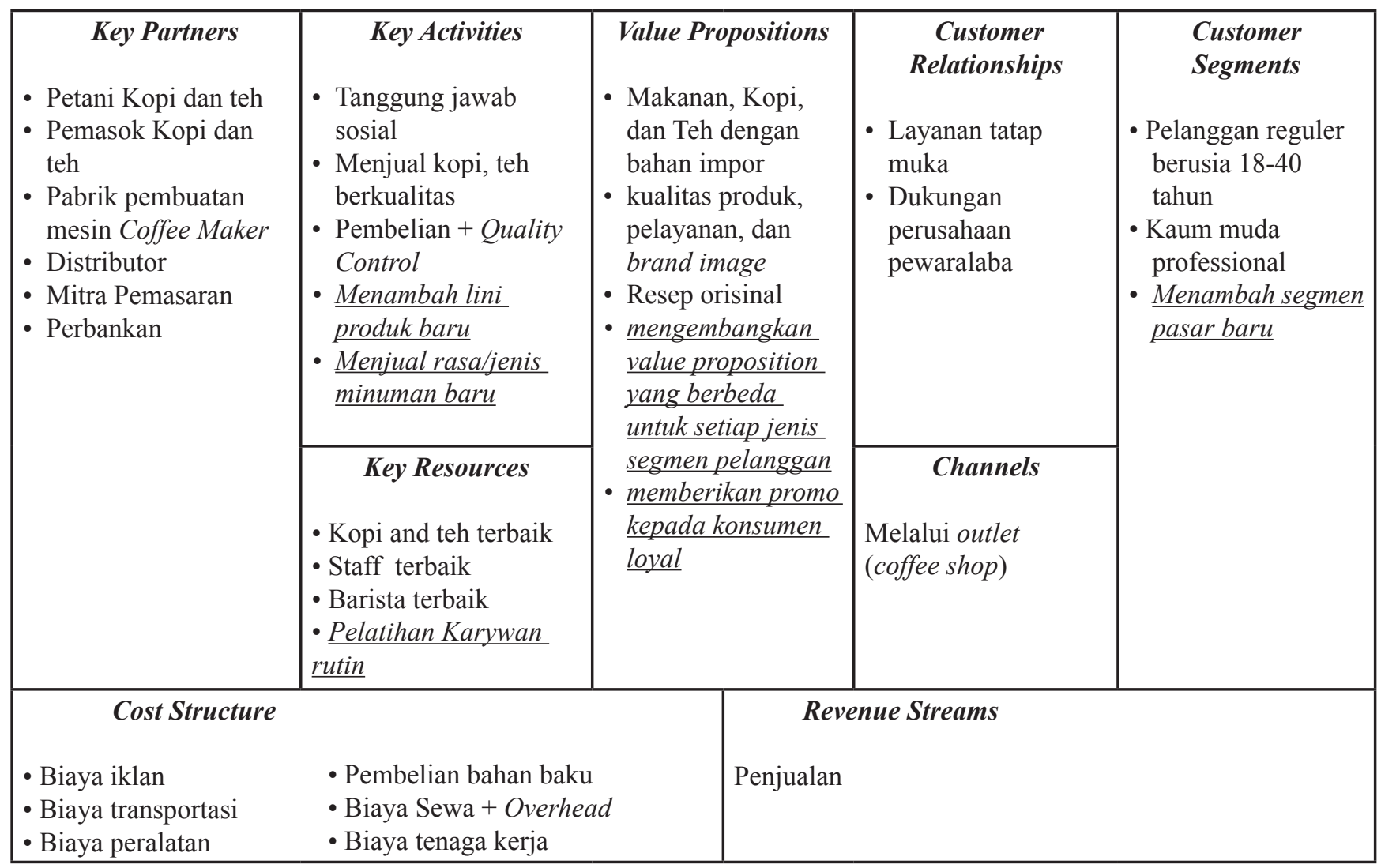

Gambar 2. Pemetaan BMC dari outlet TCBTL Cilandak Town Square 


\section{Implikasi Manajerial}

Setiap perusahaan memiliki strategi masing-masing dalam melakukan perbaikan manajemennya. Strategi yang diambil bisa bersumber dari keputusan pimpinan, keputusan rutin atau keputusan yang diambil dari hasil penelitian. Implikasi manajerial adalah sebuah cara yang diperlukan untuk mencapai tujuan strategis perusahaan. Implikasi manajerial hasil penelitian ini didasarkan pada program perbaikan dalam BMC. Perbaikannya berada pada empat elemen, yaitu costumer segment, value proposition, key activity dan key resources. Berdasarkan keempat elemen tersebut maka masukan terhadap implikasi manajerial TCBTL, yaitu sebagai berikut: Membuat diversifikasi produk dan harga khusus untuk kalangan mahasiswa atau pelajar disesuaikan dengan daya belinya; Membuat rasa baru untuk minuman kopi dan teh dengan kemasan yang baru sehingga semakin banyak pilihan bagi konsumen yang loyal; Membuat kompetisi karyawan outlet TCBTL Cilandak Town Square untuk meningkatkan motivasi kerja dan memberikan reward bagi karyawan yang berprestasi; Pelatihan karyawan yang lebih baik sehingga semua karyawan memiliki kualitas yang sama untuk melaksanakan tugas atau peran kerjanya; dan Melakukan promo khusus pada acara-acara tertentu di Cilandak Town Square seperti acara fashion show, ladies day, jazzy night dan acara lainnya.

\section{KESIMPULAN DAN SARAN}

\section{Kesimpulan}

Hasil penelitian komponen elemen BMC (customer segmentations, value propositions, channels, customer relationships, revenue streams, key resources, key activities, key partnerships dan cost structures) maka program perbaikan yang harus dilakukan oleh TCBTL melalui identifikasi faktor eksternal dan internal adalah, mengoptimalkan fungsi bank sebagai mitra yang mampu meningkatkan penjualan melalui program promosi kepada pemegang kartu atau nasabah pada elemen mitra utama. Kegiatan utama elemen yang perlu ditingkatkan TCBTL adalah menambahkan mitra kerja untuk meningkatkan kerjasama dalam melakukan kegiatan pemasaran. Kemudian pada elemen sumber daya manusia, TCBTL perlu meningkatkan pelatihan karyawan, insentif yang transparan dan rutin serta merancang strategi peningkatan kapasitas SDM yang dimiliki.
Hasil analisis SWOT maka outlet TCBTL Cilandak Town Square dapat melakukan perbaikan sebagai berikut: a) Memperkenalkan minuman atau rasa baru, yang bertujuan agar TCBTL masuk ke target pasar yang baru, misalnya pelajar usia 15 tahun; b) Fokus pada target konsumen yang lebih spesifik seperti profesional muda, pebisnis, pengusahayang berkunjung ke Cilandak Town Square; c) Meningkatkan layanan pelanggan dengan cara komunikasi dan interaksi langsung dengan pelanggan yang datang; d) Meningkatkan lini produk, sehingga dapat mengantisipasi banyaknya produk substitusi kopi dipasaran; e) Meningkatkan penggunaan media promosi seperti kerja sama dengan bank, provider telekomunikasi, website dan media sosial (facebook, instagram, path); F) Melakukan pelatihan kepada karyawan untuk peningkatan kapasitas sumber daya manusia.

\section{Saran}

Dari hasil penelitian maka saran yang dapat diberikan adalah a) Pelaku usaha dan pemangku kepentingan lainnya, termasuk peneliti dalam melakukan analisis model bisnis dapat menggunakan pendekatan lain atau mengkombinasikannya dengan teori lain, misal menggunakan business modeling map, atau mengombinasikan antara business model canvas dengan pemetaan pikiran (mind map), sesuai dengan kondisi maupun situasi yang ada; dan b) Mengidentifikasi perbaikan model bisnis dapat dilakukan dengan pendekatan lain, misalnya menggunakan analisis industri, balance score card, PESTEL, atau analisis rantai nilai (value chain).

\section{DAFTAR PUSTAKA}

[AEKI] Asosiasi Eksportir Kopi Indonesia. 2014. Perkembangan ekspor kopi Indonesia (20072013).http://www.aeki-aice.org/page/realisasiekspor-impor-kopi-ndonesia-th-2013/id.[18 April 2015].

Amanullah ANA, Aziz NFB, Hadi FN, Ibrahim J. 2016. Comparison of business model canvas (BMC) among the three consulting companies. International Journal of Computer Science and Information Technology Research 3(2): 462471.

Bachdar S. 2014. Langkah Starbucks setelah buka 200 gerai di Indonesia. http://marketeers.com/article/ langkah-starbucks-setelah-buka-200-gerai-di- 
indonesia.html [19 September 2015].

Fielt E. 2013. Conceptualising Business Models: Definitions, Frameworks and Classifications. Journal of Business Models 1(1): 85-105.

Florencia B. 2015. Business model canvas pada CV Sekawan Cosmetics Sidoarjo. Agora 3 (1): 207214.

Horvath L, Csik O, Misley H, Nagy K, Verderber E. 2016. The business model canvas as a tool for assessing curriculum implementation effectiveness in a Hungarian private secondary school. Journal of Medical Systems 40(144):1-9.

[ICO] International Coffe Organization. 2014. Consumsion of coffee. http://www.ico.org/ prices/new-consumption-table.pdf. $\left[\begin{array}{ll}1 & \text { April }\end{array}\right.$ 2015].

Kara A, Kaynak E, Kucukemiroglu O. 1997. Marketing strategies for fast food restaurants: a customer view. British Food Journal 14 (5): 245-257.

Kurniawan A, Ridlo MR. 2017. Perilaku konsumtif remaja penikmat warung kopi. Jurnal Sosiologi DILEMA 32(1): 9-22.

Lamarque E. 2005. Identifiying key activities in banking firms: A competence-based analysis. Journal of Emerald Group Publishing Limited 10(7): 2947.

Leschke J. 2013. Business model mapping: a new tool to encourage entrepreneurial activity and accelerate new venture creation. Journal of Marketing Development and Competitiveness 2 (7): 45-58.

Mawson E, Fearne A. 1996. Purchasing strategies and decision-making processes in the food service industry: a case study of UK restaurant chains. Supply Chain Management International Journal 1(3): 34-41. https://doi. org/10.1108/13598549610155305.

Morris L. 2009. Business model warfare: the strategy of business breakthroughs. An Innovation Labs
White Paper,prepared dan published jointly with A-CASA, The University of Pennsylvania 8(2): $1-28$.

Muller RM, Kijl B, Martens JK. 2011. A comparison of interorganizational business models of mobile app stores: There is More than Open vs. Closed. Journal 24 (2): 234-245.

Qastharin RA. 2016. Business model canvas for social enterprise. Journal of Business and Economics 7(4): 627-637.

Rahardjo P. 2012. Panduan Budidaya dan Pengolahan Kopi Arabika dan Robusta. Jakarta: Penebar Swadaya.

Rytkonen E, and Nenonen S. 2013. The Business Model Canvas in university campus management. Intelligent Buildings International 6(3): 138154. https://doi.org/10.1080/17508975.2013.80 7768.

Salendra. 2014. Coffee shop as a media for selfactualization today's youth. Jurnal Messenger 4(2): 7-19.

Silalahi. 2014. Analisis model bisnis pada divisi agribisnis Bank Rakyat Indonesia menggunakan pendekatan business model canvas [tesis]. Bogor: Sekolah Pascasarjana, Intstitut Pertanain Bogor.

Stefan S, Richard B. 2014. Analysis of business models. Journal of Competitiveness 6(4):19-40. https:// doi.org/10.7441/joc.2014.04.02.

Teece DJ. 2009. Business models, business strategy and innovation. Long Range Planning 4 (2): 72-89.

Widjadja W, Jokom. 2007. Analisis penilaian konsumen terhadap ekuitas merek Coffee Shops di Surabaya. Jurnal Manajemen Perhotelan 3(2):89-101.

ZottC,AmitR. 2013. The business model:Atheoretically anchored robust construct for strategic analysis. Strategic Organization 11(4): 403-411. https:// doi.org/10.1177/1476127013510466. 